\title{
Eye Tracking Technology in Detecting the Switch Cost in the Intra-sentential Code-Switching Contexts
}

\author{
https://doi.org/10.3991/ijet.v13i05.8109 \\ Liqin $\mathrm{Wu}^{(凶)}$, Cuihua $\mathrm{Xi}$ \\ Anhui University of Finance and Economics, Bengbu, China \\ lilywulq@126.com
}

\begin{abstract}
Switch cost and cost site have been controversial issues in the code-switching studies. This research conducted an eye tracking experiment on eight bilingual subjects to measure their switch cost and cost site in comprehending the intra-sentential code-switching (Chinese and English) and the unilingual (pure Chinese) stimuli. The English words and their Chinese translations or equivalents were assumed as the key words in either a unilingual or an intra-sentential code-switching paragraph. These key words were located as areas of interest (AOI) with the same height and consisted of three wordfrequency levels. After the experiment, the subjects were required to do a comprehension test to ensure their real understanding of the English words. Their performances in two different reading contexts were compared by adopting a paired sample t-test. Their eye movement data were validated by using 2 x 3 repeated measures ANOVA. It was revealed that: 1) the subjects' scores in the intra-sentential code-switching contexts were higher than those in the unilingual ones, i.e. reading efficiency increased in the intra-sentential code-switching contexts; 2) word frequency had little effect on word recognition speed in the intra-sentential code-switching contexts, i.e., the least frequently used words did not necessarily take the subjects' more time or vice versa; 3) even if a switch cost occurred(on rare occasions), it was not necessarily at the switching site, and low frequency words in alternating languages did impair performance even when the switch occurred at a sentence boundary.
\end{abstract}

Keywords-eye tracking; switch cost; unilingual; intra-sentential codeswitching; word frequency

\section{Introduction}

Most studies for switch cost derive from the lexical-decision-task study revolving around the words or non-words in two different languages with similar lexical features [1]. However, this research compared subjects' comprehension performances in the pure Chinese-unilingual and the Chinese-English-intra-sentential codeswitching (a code switch that occurs within a sentence or a clause) contexts which have different orthographic systems. Different word-frequency levels were also taken into account since word frequencies are often considered to be the main cause of the switch cost. 
Eye tracking technology was applied in the study because of its being a sensitive indicator of a range of properties of the words being read in the past four decades researches on different languages reading [2][3]. An experiment was designed to answer the following questions: 1) Is there a switch cost in an intra-sentential codeswitching reading? If there is, does it occur at the switch site? 2) Does word frequency have any impact on recognition speed in the intra-sentential code-switching contexts?

\section{$2 \quad$ Literature Review}

The switch cost and cost site have been popular topics in the code-switching studies by scholars in different parts of the world from different perspectives. Their researching findings can be roughly classified into two conflicting views: pro and con.

Some code-switching or code-mixing (here the two terms are used interchangeably) studies indicate that a code switch during comprehension of visually presented words leads to a switch cost in individual's performance. Performance suffers when bilinguals must switch between comprehending words in each of their languages [4]. It was demonstrated that bilinguals were slower to read texts aloud when the passages were written in two languages rather than of a single language [5], and that mixed lists were slower than pure lists during silent reading [6][7] and during lexical decision [1]. Alternating languages randomly within sentences generated anomalous syntactic patterns which bilinguals were unaccustomed to and this alone could generate slower responding relative to unilingual sentences[6][8]. Psychological studies further revealed that in a bilingual priming paradigm, bilinguals took longer to respond to targets preceded by a different language prime than a same language prime [9][10]. And trials requiring a code switch in lexical decision produced longer reaction times than those in a sequence of the same language trials [11][12]. Some of the cost site studies showed that alternating languages did not impair performance when the switch occurred at sentence boundaries, i.e., when sentence structure was not affected [5]. And the use of language-specific orthographic cues could eliminate these costs [1].

However, other studies have proved that there is no significant cost incurred by inter-sentential language switching or mixing (a code switch that occurs between sentences) when bilinguals read sentences for comprehension [13]. In contrast to lexical switching from one language to the other, inter-sentential code-switching of the sort in which bilinguals frequently engage, imposes no significant costs to lexical processing [14]. They think that under normal circumstances and given sufficient linguistic context, language switching does not incur a cost. When making metalinguistic judgments and performing non-comprehension based tasks, switch costs were evident but there was no evidence to support the hypothesis that there is a cost at the switch site when bilinguals read a mixed sentence [15]. The experiments by Thomas \& Allport [4] indicated that the switch cost originated from outside rather than inside the bilingual lexicon. 
To make code-switching studies more convincing and concise, people started to use a new technology - eye tracking. The first use of eye trackers in the study of human visual attention was those conducted by such scholars as Rayner in reading and other information processing tasks [16]. By combining reading efficiency with word frequency, studies have shown that eye movements during reading for comprehension are sensitive to differences in word frequency. Words that are encountered more frequently are processed faster than their less frequent counterparts [17]. Words with higher frequency are typically processed more quickly and accurately than words with lower frequency [18]. Readers with higher comprehension scores (who perhaps were reading more carefully) showed larger word frequency effects than readers with lower comprehension scores [19].

Different from the above studies, this paper used eye tracking technology together with a paper test to detect the switch cost and cost site in the intra-sentential codeswitching contexts, aiming at contributing some code-switching findings on different orthographic features to the system of code-switching researches.

\section{$3 \quad$ Methodology}

To find out answers to the switch cost and cost site in the intra-sentential codeswitching contexts, the researcher used a quantitative approach to measure data from both an eye movement experiment on subjects and the subjects' test performances. One-way ANOVA was used to validate the difficulty level of reading comprehension. A paired sample t-test was applied to compare the subjects' performances in two different reading contexts. Repeated measures ANOVA within the areas of interest (AOI) was adopted to test the main and interactive effects.

\subsection{Experimental Design}

This is a $2 \times 3$ experimental design. TWO here refers to the language that is either intra-sentential code-switching or unilingual. THREE refers to the three wordfrequency levels: high, middle and low.

The English words and their Chinese translations or equivalents were assumed as the key words that were located as AOI marked off by the same height. Before an analysis was made, all the numbers obtained were divided by the AOI size and multiplied by 10,000 to avoid the length disparity of English letters and Chinese characters.

In this eye tracking, there were five observed points: 1) first fixation duration (FFD) (ms): time spent on the first fixation within an AOI; 2) fixation time total (FTT) (ms): the total time spent on fixations within an AOI; 3) fixation count total (FCT) (ms): the total sum of fixation within an AOI; 4) revisits total (RT) (ms): the total sum of revisited fixation within an AOI; and 5) dwell time total (DTT) (ms): the total cumulative fixation time within an AOI, including the total time of glances and fixation within an AOI. 


\subsection{Subjects}

In the experiment 8 subjects were selected from a major university in East China. Four females and four males. Their age varied from 18 to 20 . All of their naked visual acuities' scores of both left and right eyes were 1.5(standard). Since all of them had passed CET Band 4 before the experiment, they were regarded as bilinguals. The College English Test, known as CET, consisting of Band 4 and Band 6, is a national English test as a foreign language for non-English majors held twice a year in China. It is generally believed that the certificate-holders of the CET Band 4 have reached the English level of non-English major undergraduate students, and the CET Band 6 certificate-holders have reached the English level of non-English major postgraduates.

\subsection{Stimuli}

Two types of reading materials were used as stimuli: one was an intra-sentential code-switching paragraph. The key word(s) made up of an English word(s)/acronym /phrase was (were) inserted in each tested Chinese paragraph; the other was a unilingual reading material, i.e., a pure Chinese paragraph. The key words made up of the Chinese translation or equivalents were inserted in each tested Chinese paragraph. The key word(s) in either the unilingual or the intra-sentential code-switching paragraph was (were) located as an AOI with the same height and consisted of three word-frequency levels.

Each type consisted of 15 paragraphs with 15 key words either in English or Chinese in different contexts and almost with the same length (around 98 Chinese characters apart from the English words). Most of the 15 English words and their equivalents occurred in the middle of the sentences in the reading materials except that $N B A$, GPS, DNA and Exchange Rate Overshooting and their Chinese equivalents were at sentence boundaries.

These 15 key words were divided evenly into three word-frequency levels according to their occurrence frequency in two China's official major media-Guangming Daily \& People's Daily within a month from June 11 to July 10 in 2013: high frequency (HF) words included four English acronyms and one blend, and their Chinese equivalents, they were the most frequently used words compared with the other two; middle frequency (MF) words consisted of four English acronyms and one blend, and their Chinese equivalents, they were more frequently used than the last level; low frequency (LF) words were composed of one compound English word and four English phrases, and their Chinese equivalents, they were the least frequently used in these three levels(See Table 1).

\subsection{Measuring Techniques}

Three measuring techniques were exploited to detect the subjects' paragraph processing cognitive activity at the very moment it took place or slightly after. 
Table 1. English Words Used in Guangming Daily \& People's Daily

\begin{tabular}{|c|c|c|c|c|c|}
\hline \multicolumn{2}{|c|}{ High Frequency } & \multicolumn{2}{c|}{ Middle Frequency } & \multicolumn{2}{c|}{ Low Frequency } \\
\hline $\begin{array}{c}\text { Acronym } \\
\text { or blend }\end{array}$ & $\begin{array}{c}\text { Total Frequency } \\
\text { (Number of Times) }\end{array}$ & $\begin{array}{c}\text { Acronym } \\
\text { or blend }\end{array}$ & $\begin{array}{c}\text { Total Frequency } \\
\text { (Number of Times) }\end{array}$ & Word or Phrase & $\begin{array}{c}\text { Total Frequencies } \\
\text { (Number of Times) }\end{array}$ \\
\hline GDP & 190 & NBA & 20 & Youtube & 1 \\
\hline Wifi & 37 & GPS & 20 & $\begin{array}{c}\text { Exchange Rate Over- } \\
\text { shooting }\end{array}$ & 1 \\
\hline WTO & 29 & CEO & 14 & geographic mobility & 1 \\
\hline CPI & 27 & UFO & 10 & $\begin{array}{c}\text { Association of Pacific } \\
\text { Rim Universities }\end{array}$ & 1 \\
\hline DNA & 22 & IMAX & 4 & $\begin{array}{c}\text { Post-Earnings- } \\
\text { Announcement Drift }\end{array}$ & 1 \\
\hline
\end{tabular}

Note: Chinese equivalents are omitted here.

a) Eye tracking: The subjects were faced with a screen on which a paragraph with the key word(s) appeared. The eye tracking recorded the subjects' eye movements and eye fixations while they read a paragraph presented on a computer screen. It documented what the subjects were looking at and how long it took them.

b) Partially rapid visual presentation: When the subjects were first presented with a paragraph, the subjects could not control the speed of reading, while the experimenter determined the presentation speed (15 seconds). The subjects were requested to read the paragraph and their reaction time to each AOI was recorded.

c) Partially self-paced reading: In the experiment, part of the task was self-paced reading. When a follow-up comprehension question with four multiple choices was presented to confirm that all the subjects had read the reading stimuli carefully, the subjects could read the question and the choices as long as they would like before they were able to answer the question orally within 5 seconds.

Each paragraph and the paragraph followed by a question with four multiple choices were photographed respectively on $1680 \times 1050$ pixel in JPG format. Photoshop was applied to ensure that all the pictures formats conform to each other: line spacing: 1.5; margin: $2 \mathrm{~cm}$ for each side; font size: 28 for both Chinese and English.

\subsection{Experimental Procedures}

After the subjects entered the laboratory, they were required to read the instructions on a piece of paper. After they had fully understood the instructions, they were arranged to sit up comfortably $60 \mathrm{~cm}$ in front of the display screen, meanwhile the eye trackers calibrated itself automatically to the best sampling positions.

The experiment consisted of two stages. At each stage, there were 30 pictures respectively, half of them were paragraph reading stimuli which were shown at random, half of them were paragraph reading stimuli with comprehension questions and four multiple choices.

Stage 1. At the first stage, the subjects were required to read within 15 seconds either the unilingual reading paragraph picture or the intra-sentential code-switching one which was displayed randomly. Then a question picture followed by four multiple choices was presented together with the same paragraph. The stimuli remained on the screen until a response had been generated, then the subjects had to answer each 
question orally within 5 seconds, and the experimenter recorded the answers and manually shifted the reading material picture to the next one.

Stage 2. After a five-minute interval, the second stage began. The subjects read within another 15 seconds the unilingual reading paragraph picture or the intrasentential code-mixing one according to what they had read at the first stage, i.e., if they had read the unilingual paragraph at the first stage, they would read the intrasentential code-mixing one, or vice versa. Then a question picture followed by four multiple choices together with the same paragraph was shown. The subjects did what they were supposed to as was mentioned at the first stage.

There was an eye tracker calibration before each stage. The experimenter recorded their eye movement track during the testing process. The whole procedure of the eye tracker is as follows:

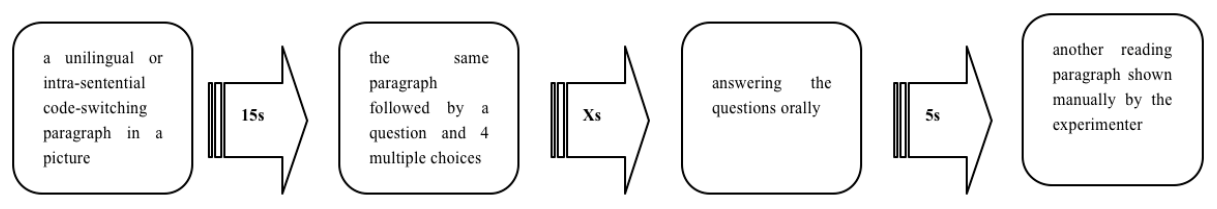

To guarantee that all the subjects did know the Chinese equivalent or Chinese translation of each English word (a jargon in most cases), and that they did not seek after the reading speed while ignoring the meaning of each English word, the subjects were demanded to do a test after the experiment. In this test, 15 Chinese sentences with 15 English words inserted in were followed by four multiple choices respectively. The subjects were asked to find out the correct meaning of each English word.

\subsection{Difficulty Level Control of the Reading Materials}

In this experiment, we inspected the validity of the difficulty control of the reading materials, and compared the subjects' reading comprehension performances and their eye movements in the intra-sentential code-switching contexts with that in the unilingual ones.

A one-way ANOVA indicated that $\mathrm{F}(2,27)=.06, \mathrm{p}>.05$, i.e., there was no significant difference in the subjects' scores on different paragraph reading comprehension.

\section{$4 \quad$ Results and Analysis}

The subjects' reading comprehension performance in the intra-sentential codeswitching contexts was compared with that in the unilingual ones. When the number of correct choice in the reading comprehension was dependent variable, it was found through the paired sample t-test that the subjects' performances in reading comprehension were strikingly different from each other between the intra-sentential codeswitching contexts $(M=6.53, S D=1.46)$ and the unilingual ones $(M=5.13, S D=$ $2.10)$. In this t-test, $t=2.25, p<.05$, it was proved that the subjects' scores in the intra-sentential code-switching contexts were higher than those in the unilingual ones. 
The test after the experiment further indicated that among the 8 subjects, 6.8 subjects on the average could choose the correct choice in each sentence, which meant that most of the subjects knew the English words and did not ignore comprehension for reading speed.

The mean (M) and standard deviation (SD) of eye movement measure within the AOI at the three different word-frequency levels are shown in Table 2.

It was found that the time that subjects spent in reading stimuli in the unilingual contexts conformed mostly to the frequencies that the key words appeared in the two China' major media. However, it was obviously different in the intra-sentential codeswitching contexts, i.e., the least frequently used words did not necessarily take the subjects' more time or the most frequently used words did not necessarily save the subjects' time. For example, in the intra-sentential code-switching contexts, the mean of FFD in HF is 297.62, but 89.20 in LF; the mean of FTT in HF is 459.46, but 377.16 in LF, 669.15 in MF; The mean of RT in HF is .52, .43 in MF and .21 in LF.

After the $2 \times 3$ repeated measures ANOVA within the AOI, the main and interactive effects are as follows (See Table 3 ).

Table 2. M and SD within the AOI at 3 Word-Frequency Levels

\begin{tabular}{|l|c|c|c|c|c|c|c|c|c|c|c|c|}
\hline & \multicolumn{4}{|c|}{ Unilingual } & \multicolumn{4}{c|}{ Intra-sentential Code-switching } \\
\hline & \multicolumn{2}{|c|}{$\boldsymbol{H} \boldsymbol{T}$} & \multicolumn{2}{c|}{$\boldsymbol{M} \boldsymbol{F}$} & \multicolumn{2}{c|}{$\boldsymbol{L F}$} & \multicolumn{2}{c|}{$\boldsymbol{H} \boldsymbol{F}$} & \multicolumn{2}{c|}{$\boldsymbol{M F}$} & \multicolumn{2}{c|}{$\boldsymbol{L F}$} \\
\hline & $M$ & $S D$ & $M$ & $S D$ & $M$ & $S D$ & $M$ & $S D$ & $M$ & $S D$ & $M$ & $S D$ \\
\hline FFD & 152.32 & 57.77 & 155.13 & 57.33 & 174.47 & 71.35 & 297.62 & 74.03 & 419.54 & 95.33 & 89.20 & 25.67 \\
\hline FTT & 601.29 & 161.98 & 608.10 & 167.60 & 887.36 & 302.36 & 459.46 & 141.40 & 669.15 & 239.52 & 377.16 & 84.43 \\
\hline FCT & 2.48 & .42 & 2.42 & .59 & 3.05 & .66 & 2.01 & .82 & 2.44 & .93 & 1.58 & .30 \\
\hline RT & .53 & .12 & .52 & .18 & .52 & .10 & .52 & .42 & .43 & .34 & .21 & .07 \\
\hline DTT & 613.38 & 164.18 & 620.08 & 174.16 & 908.03 & 305.06 & 469.36 & 138.95 & 670.85 & 241.86 & 392.98 & 89.59 \\
\hline
\end{tabular}

Table 3. $2 \times 3$ Repeated Measures ANOVA within the AOI

\begin{tabular}{|c|c|c|c|c|}
\hline & Intra-sentential Code-switching (or Unilingual) \& Frequency Levels & $\mathbf{F}$ & Sig. & $\eta 2$ \\
\hline \multirow{3}{*}{ FFD } & Intra-sentential Code-switching (or Unilingual) & $28.29 * *$ & .001 & .80 \\
\hline & Frequency Levels & $37.75 * * *$ & .000 & .84 \\
\hline & Intra-sentential Code-switching (or Unilingual) *Frequency Levels & $46.73 * * *$ & .000 & .87 \\
\hline \multirow{3}{*}{ FTT } & Intra-sentential Code-switching (or Unilingual) & $7.44 *$ & .029 & .52 \\
\hline & Frequency Levels & 1.40 & .280 & .17 \\
\hline & Intra-sentential Code-switching (or Unilingual) *Frequency Levels & $18.37 * * *$ & .000 & .72 \\
\hline \multirow{3}{*}{ FCT } & Intra-sentential Code-switching(or Unilingual) & $8.92 *$ & .020 & .56 \\
\hline & Frequency Levels & .27 & .772 & .04 \\
\hline & Intra-sentential Code-switching (or Unilingual) *Frequency Levels & $12.26 * *$ & .001 & .64 \\
\hline \multirow{3}{*}{ RT } & Intra-sentential Code-switching (or Unilingual) & 2.26 & .177 & .24 \\
\hline & Frequency Levels & 1.57 & .243 & .18 \\
\hline & Intra-sentential Code-switching(or Unilingual) *Frequency Levels & 2.50 & .118 & .26 \\
\hline \multirow{3}{*}{ DTT } & Intra-sentential Code-switching(or Unilingual) & $7.73 *$ & .027 & .53 \\
\hline & Frequency Levels & 1.44 & .270 & .17 \\
\hline & Intra-sentential Code-switching (or Unilingual) *Frequency Levels & $17.22 * * *$ & .000 & .71 \\
\hline
\end{tabular}

Note: $*$ signifies $\mathrm{p}<.05, * * \mathrm{p}<.01$, and $* * * \mathrm{p}<.001$

Through the repeated measures ANOVA within the AOI, the results are: 


\subsection{First Fixation Duration}

In the first fixation duration (FFD), the main effect between intra-sentential codeswitching and unilingual contexts was comparatively significant, $F(1,7)=28.29$, $\mathrm{p}<.05, \eta 2=.80$. And it took the subjects longer time in the intra-sentential codeswitching contexts $(\mathrm{M}=268.79, \mathrm{SE}=18.40)$ than that in the unilingual ones $(\mathrm{M}=160.64, \mathrm{SE}=18.50)$.

The main effect of word-frequency levels was very significant, $F(2,14)=37.75$, $p<.05, \eta^{2}=.84$. At the three word-frequency levels, the difference between HF and MF, or the difference between HF and LF, or the difference between MF and LF, was very significant. Time consumption from the most to the least in FFD was $\mathrm{MF}>\mathrm{HF}>\mathrm{LF}$.

The interactive effect between intra-sentential code-switching and unilingual contexts and word-frequency levels was very significant, $F(2,14)=46.73, p<.05, \eta^{2}=.87$. Simple effect analysis revealed that at three different word-frequency levels there was a significant difference between intra-sentential code-switching and unilingual contexts, and FFD in MF and HF was longer when the language was intra-sentential code-switching, but FFD in LF was longer when the language is unilingual. And there was not a significant difference at the three different levels when the language was unilingual. In the intra-sentential code-switching contexts, the difference between HF and MF, or the difference between HF and LF, or the difference between MF and LF, was significant. Time consumption from the most to the least in FFD was $\mathrm{MF}>\mathrm{HF}>\mathrm{LF}$.

\subsection{Fixation Time Total}

The main effect between intra-sentential code-switching and unilingual contexts was significant, $F(1,7)=7.44, p<.05, \eta^{2}=.52$. Fixation time total (FTT) in the unilingual contexts $(M=698.92, S E=57.47)$ was longer than that in the code-switching ones $(M=501.93, S E=35.30)$.

The main effect of word-frequency levels was NOT significant, $F(2,14)=1.40$, $p>.05$.

The interactive effect between intra-sentential code-switching (or unilingual) and word-frequency levels was significant, $F(2,14)=18.37, p<.05, \eta^{2}=.72$. Simple effect analysis revealed that only in LF the difference was significant. In the unilingual contexts, FTT was longer; there were significant differences among the three word-frequency levels; and FTT in LF was longer; there were NOT significant differences between $\mathrm{HF}$ and MF. In the intra-sentential code-switching contexts, there were significant differences between MF and LF, between MF and HF; FTT in MF was longer; there were NOT significant differences between HF and LF. 


\subsection{Fixation Count Total}

The result of Mauchly's Sphericity Test indicated that the main effect of the wordfrequency levels violated the spherical assumption, $\chi 2(2)=8.66, p<.05$, GreenhouseGeisser Correction was used to correct the degrees of freedom $(\varepsilon=.57)$.

The main effect between intra-sentential code-switching and unilingual contexts was significant, $F(1,7)=8.92, p<.05, \eta^{2}=.56$. There were more fixation counts in the unilingual contexts $(M=2.65, S E=.12)$ than those in the intra-sentential codeswitching ones $(M=2.01, S E=.18)$.

The main effect of word-frequency levels was NOT significant, $F(2,14)=.27$, $\mathrm{p}>.05$.

The interactive effect between intra-sentential code-switching and unilingual contexts and word-frequency levels was more significant, $F(2,14)=12.26, p<.05, \eta$ ${ }^{2}=.64$. Simple effect analysis revealed that only in LF there was a significant difference between intra-sentential code-switching and unilingual contexts. In the unilingual contexts, there were more fixation counts; there was a significant difference between HF and LF, and there were more fixation counts in LF. There was no significant difference among the three word-frequency levels in the intra-sentential codeswitching contexts.

\subsection{Revisits Total}

Neither the main effect between intra-sentential code-switching and unilingual contexts nor that of word-frequency levels was significant.

The interactive effect between intra-sentential code-switching and unilingual contexts and word-frequency levels was NOT either significant.

\subsection{Dwell Time Total}

The result of Mauchly's Sphericity Test indicated that the main effect of the wordfrequency levels violated the spherical assumption, $\chi 2(2)=6.06, p<.05$, GreenhouseGeisser Correction was used to correct the degrees of freedom $(\varepsilon=.61)$.

The main effect between intra-sentential code-switching and unilingual contexts was significant, $F(1,7)=7.73, p<.05, \eta^{2}=.53$, Dwell time was longer in the unilingual contexts $(M=713.83, S E=58.67)$ than in the intra-sentential code-switching ones $(M=511.06, S E=35.84)$.

The main effect of word-frequency levels was NOT significant, $F(2,14)=1.44$, $\mathrm{p}>.05$.

The interactive effect between intra-sentential code-switching and unilingual contexts and word-frequency levels was very significant, $F(2,14)=17.22, p<.05, \eta^{2}=$ .71. Simple effect analysis revealed that only in LF there was a significant difference between intra-sentential code-switching and unilingual contexts. In the unilingual contexts, there was more dwell time; there was a significant difference between LF and the other two word-frequency levels, and dwell time in LF was longer; but no significant difference between HF and MF. On the contrary, in the intra-sentential 
code-switching contexts, there was a significant difference between MF and the other two word-frequency levels, and dwell time in MF was longer, but no significant difference between HF and LF.

The results of eye movement measure (See Table 4) provides us with a whole picture of the experiment outcome.

Table 4. The Results of Eye Movement Measure

\begin{tabular}{|c|c|c|c|}
\hline FFD & A Significant & B Significant & A*B Significant \\
\hline & $\mathrm{A} 2>\mathrm{A} 1$ & $\begin{array}{l}\text { Significant when compared in } \\
\text { pairs, and B2 }>\text { B1 }>\text { B3 }\end{array}$ & $\begin{array}{l}\text { When B1, B2, A2>A1. } \\
\text { When B3, A1>A2. }\end{array}$ \\
\hline & & & $\begin{array}{l}\text { When A1, NOT Significant. } \\
\text { When A2, significant when compared in } \\
\text { pairs, and B2 }>\text { B1 }>\text { B3. }\end{array}$ \\
\hline \multirow[t]{3}{*}{ FTT } & A Significant & B NOT Significant & A*B Significant \\
\hline & $\mathrm{A} 1>\mathrm{A} 2$ & & $\begin{array}{l}\text { When B1, B2, NOT Significant. } \\
\text { When B3, A1>A2. }\end{array}$ \\
\hline & & & $\begin{array}{l}\text { When A1, B3>B1, B2. } \\
\text { When A2, B2>B1, B3. }\end{array}$ \\
\hline \multirow[t]{3}{*}{ FCT } & A Significant & B NOT Significant & A*B Significant \\
\hline & $\mathrm{A} 1>\mathrm{A} 2$ & & $\begin{array}{l}\text { When B1,B2, NOT significant. } \\
\text { When B3, A1>A2. }\end{array}$ \\
\hline & & & $\begin{array}{l}\text { When A1, B3>B1. } \\
\text { When A2, NOT significant. }\end{array}$ \\
\hline RT & A NOT Significant & B NOT Significant & A*B NOT Significant \\
\hline \multirow[t]{3}{*}{ DTT } & A Significant & B NOT Significant & A*B Significant \\
\hline & $\mathrm{A} 1>\mathrm{A} 2$ & & $\begin{array}{l}\text { When B1, B2, NOT significant. } \\
\text { When B3, A1>A2. }\end{array}$ \\
\hline & & & $\begin{array}{l}\text { When A1, B3>B1, B2. } \\
\text { When A2, B2>B1, B3. }\end{array}$ \\
\hline
\end{tabular}

Note: A signifies intra-sentential code-switching or unilingual; A1 for unilingual; A2 for intra-sentential code-switching; B for word-frequency levels; B1 for HF, B2 for MF, and B3 for LF.

\section{Discussion}

The results from the experiment here lead to a further discussion of language switching costs and word frequency. Through FFD, FTT, FCT, RT and DTT five observed points, it was demonstrated that in most cases the time subjects spent in the unilingual contexts was longer than that in the intra-sentential code-switching ones except in FFD and RT. Heat maps (omitted here) showed that even when a switching cost occurred; it was not necessarily at the switching site. Therefore, there is no evidence to support the hypothesis that there is a cost at the switch site when bilinguals read a mixed sentence, which partly echoes Guzzardo Tamargo' findings [15].

Word frequency played a minor role in word recognition except in FFD where the time sequence was $\mathrm{MF}>\mathrm{HF}>\mathrm{LF}$ instead of $\mathrm{HF}>\mathrm{MF}>\mathrm{LF}$. Heat maps also revealed that in the intra-sentential code-switching contexts, the time spent on the English words "Wifi", "WTO" and "exchange rate" respectively was longer even if their wordfrequency levels were HF and LF.

When both the intra-sentential code-switching contexts and word-frequency levels were considered, the differences were very significant on the whole except in RT. At 
HF and MF levels, the differences were not significant except in RT and FFD wherein the subjects took longer time in the intra-sentential code-switching contexts. At LF level, it took the subjects longer time in the unilingual contexts except in RT. In the unilingual contexts, LF words took the subjects longer time except in RT, but in the intra-sentential code-switching ones, the time spent in MF words was longer except in $\mathrm{RT}$ and FCT where the difference was not significant.

The experimental results indicated that it took the subjects less time comprehending the target language which was against the switching cost theory. A partial conclusion may be drawn that given sufficient linguistic context, language switching for Chinese-English bilinguals does not incur a cost, which conforms to Gullier et al's view [14]. And the results also trigger another possibility: Lexical candidates from different languages that DO NOT share similar lexical features are co-activated when a word is presented. Or might it suggest that the recognition of a word is processed in parallel for both languages and the lexical information of both languages are activated in which case lexical access is language non-selective[20][21]. Contrary to Kolers' finding[5], it was found from the heat map that the English words "exchange rate" occurred at a sentence boundary, but its fixation duration was longer. The possible reason may be that it is a jargon or technical term instead of a common one. That the subjects' performance demonstrated that the subjects' scores in the intra-sentential code-switching contexts were higher than those in the unilingual ones enables us to believe that the intra-sentential code-switching between Chinese and English makes bilinguals read more efficiently.

\section{$6 \quad$ Limitations and Future Studies}

Despite the use of the new technology of eye tracking and the great efforts made by the researcher, there are some limitations in the study. For example, samples used here are inadequate. Only eight subjects and two major media were selected as samples because of the insufficient fund. The results would be more persuasive if more subjects and media had been considered.

With the emergence of new technology, future studies in switch cost and cost site will become more interdisciplinary and sophisticated. They may cover a variety of disciplines such as neurology, psychology, linguistics, mathematics, computer linguistics, and statistics. Methodologies available will be wide and varied. Eye tracking will become one of the commonest practices. There will be more options for the researchers to choose from.

\section{Acknowledgements}

This research is supported by Humanities and Social Sciences Planned Project Fund, the Ministry of Education of PRC (13YJAZH097), and by Humanities and Social Sciences Youth Project Fund, the Ministry of Education of PRC (17YJC740109). 


\section{References}

[1] Grainger, J., \& Beauvillain, C. (1987). Language blocking and lexical access in bilinguals. Quarterly Journal of Experimental Psychology, 39A, 295-319. https://doi.org/10.1080/146 $\underline{40748708401788}$

[2] Rayner, K. (1998). Eye movements in reading and information processing: 20 years of research. Psychological Bulletin, 124, 372-422. https://doi.org/10.1037/0033-2909.124.3.372

[3] Rayner, K. (2009). The thirty-fifth Sir Frederick Barlett lecture: Eye movements and attention in reading, scene perception, and visual search. The Quarterly Journal of Experimental Psychology, 62, 1457-1506. https://doi.org/10.1080/17470210902816461

[4] Thomas, M. S. C. \& Allport, A. (2000). Language switching costs in bilingual visual word recognition. Journal of Memory and Language, 43, 44-66. https://doi.org/10.1006/jmla.19 99.2700

[5] Kolers, P. A. (1966). Interlingual facilitation in short-term memory. Journal of Verbal Learning and Verbal Behaviour, 5, 314-319. https://doi.org/10.1016/S00225371(66)80037-3

[6] Dalrymple-Alford, E. C. (1985). Language switching during bilingual reading. British Journal of Psychology, 76, 111-122. https://doi.org/10.1111/j.2044-8295.1985.tb01935.x

[7] Macnamara, J., \& Kushnir, S. (1971). Linguistic independence in bilinguals: The input switch. Journal of Verbal Learning and Verbal Behaviour, 10, 480-487. https://doi.org/10.1016/S0022-5371(71)80018-X

[8] Paradis, M. (1980). The language switch in bilinguals: Psycholinguistic and neurolinguistic perspectives. In P. Nelde (ed.), Languages in Contact and Conflict. Wiesbaden, Federal Republic of Germany: Franz Steiner Verlag.

[9] Grainger, J., \& Beauvillain, C. (1988). Associative priming in bilinguals: Some limits of interlingual facilitation effects. Canadian Journal of Psychology, 42, 261-273. https://doi.org/10.1037/h0084193

[10] Grainger, J., \& O'Regan, J. K. (1992). A psychophysical investigation of language priming effects in two English-French bilinguals. European Journal of Cognitive Psychology, 4, 323-339. https://doi.org/10.1080/09541449208406191

[11] Thomas, M. S. C., \& Allport, A. (1995, September). The dynamic control of bilinguals' lexical representations. Paper presented at the British Psychological Society Cognitive Section Annual Conference, Bristol, UK.

[12] Von Studnitz, R. E., \& Green, D. W. (1997). Lexical decision and language switching. International Journal of Bilingualism, 1, 3-24. https://doi.org/10.1177/136700699700100102

[13] Ibáñez, A.; P. Macizo; M. Bajo (2010). Language access and language selection in professional translators. Acta Psychol, 135, 257-266. https://doi.org/10.1016/j.actpsy.2010.07.0 $\underline{09}$

[14] Gullifer, J. W., Kroll, J. F. and Dussias, P. E. (2013). When language switching has no apparent cost: lexical access in sentence context. Frontiers in Psychology, 4, 1-13. https://doi.org/10.3389/fpsyg.2013.00278

[15] Guzzardo Tamargo, R.E. (2012). Linking Comprehension Costs to Production Patterns During the Processing of Mixed Language. University Park: The Pennsylvania University.

[16] Rodrigues, Pedro \& Rosa, Pedro J. (2017) Eye tracking as a research methodology in educational context: A spanning framework. In Christopher Was et al (ed.), Eye Tracking Technology Applications in Educational Research, Hershey, PA, USA: IGI Global. https://doi.org/10.4018/978-1-5225-1005-5.ch001 
Paper-Eye Tracking Technology in Detecting the Switch Cost in the Intra-sentential Code-Switching ...

[17] Inhoff, A. W., \& Rayner, K. (1986). Parafoveal word processing during eye fixations in reading: Effects of word frequency. Perception \& Psychophysics, 40, 431-439. https://doi.org/10.3758/BF03208203

[18] White, S. J. Warrington, K. L. McGowan, V. A. and Paterson, K. B. (2015). Eye movements during reading and topic scanning: effects of word frequency. Journal of Experimental Psychology: Human Perception and Performance. 41, 1, 233-248. https://doi.org/10.1037/xhp0000020

[19] Whitford, V., \& Titone, D. (2014). The effects of reading comprehension and launch site on frequency-predictability interactions during paragraph reading. The Quarterly Journal of Experimental Psychology, 67, 1151-1165. https://doi.org/10.1080/17470218.2013.8482 $\underline{16}$

[20] Kroll, J. F., \& Tokowicz, N. (2005). Models of bilingual representation and processing. Handbook of bilingualism: Psycholinguistic approaches, 531-553.

[21] Wu, Liqin (2015). The processes of word production in a bilingual code-switching context. Foreign Language Research, 5, 123-126.

\section{Authors}

Liqin $\mathbf{W u}$ is a professor of Anhui University of Finance and Economics,Bengbu, China.

Cuihua Xi is an associate professor of East China Normal University, Shanghai, China.

Article submitted 13 December 2017. Resubmitted 11 and 25 February 2018. Final acceptance 25 March 2018. Final version published as submitted by the authors. 